\title{
From accuracy to patient outcome and cost- effectiveness evaluations of diagnostic tests and biomarkers: an exemplary modelling study
}

\author{
Hendrik Koffijberg ${ }^{1 *}$, Bas van Zaane ${ }^{2}$ and Karel GM Moons ${ }^{1,2}$
}

\begin{abstract}
Background: Proper evaluation of new diagnostic tests is required to reduce overutilization and to limit potential negative health effects and costs related to testing. A decision analytic modelling approach may be worthwhile when a diagnostic randomized controlled trial is not feasible. We demonstrate this by assessing the cost-effectiveness of modified transesophageal echocardiography (TEE) compared with manual palpation for the detection of atherosclerosis in the ascending aorta.

Methods: Based on a previous diagnostic accuracy study, actual Dutch reimbursement data, and evidence from literature we developed a Markov decision analytic model. Cost-effectiveness of modified TEE was assessed for a life time horizon and a health care perspective. Prevalence rates of atherosclerosis were age-dependent and low as well as high rates were applied. Probabilistic sensitivity analysis was applied.

Results: The model synthesized all available evidence on the risk of stroke in cardiac surgery patients. The modified TEE strategy consistently resulted in more adapted surgical procedures and, hence, a lower risk of stroke and a slightly higher number of life-years. With $10 \%$ prevalence of atherosclerosis the incremental cost-effectiveness ratio was $€ 4,651$ and $€ 481$ per quality-adjusted life year in 55-year-old men and women, respectively. In all patients aged 65 years or older the modified TEE strategy was cost saving and resulted in additional health benefits.

Conclusions: Decision analytic modelling to assess the cost-effectiveness of a new diagnostic test based on characteristics, costs and effects of the test itself and of the subsequent treatment options is both feasible and valuable. Our case study on modified TEE suggests that it may reduce the risk of stroke in cardiac surgery patients older than 55 years at acceptable cost-effectiveness levels.
\end{abstract}

Keywords: Diagnostic test, Patient outcomes, Cost-effectiveness analysis, Stroke, Cardiac surgery

\section{Background}

The number of diagnostics tests and (bio)markers available in medical practice has been increasing rapidly over the past decades and is likely to increase even further given the quest for stratified and personalized medicine. Consequently, there is growing concern about the overutilization of diagnostic tests and markers, the potential negative health consequences due to over testing, and the steeply rising costs for diagnostic testing [1,2]. To avoid these problems proper evaluation of the downstream

\footnotetext{
* Correspondence: h.koffijberg@umcutrecht.nl

'Julius Centre for Health Sciences and Primary Care, University Medical Centre Utrecht, Mailstop STR 6.131, P.O. Box 85500, Utrecht, GA 3508, The Netherlands

Full list of author information is available at the end of the article
}

consequences or benefits, in terms of improved decision making and patient outcomes, as well as on the costbenefits of diagnostic testing, is required [3-11]. However, the evaluation of diagnostic tests and markers typically stops after quantifying the accuracy of the test or marker as compared to the prevailing reference standard [4-6,811]. The consequences of diagnostic testing strategies may be quantified comprehensively in randomized clinical trials (RCT). However, RCTs of diagnostic strategies are not always recommended since they are often too costly and time consuming. They are also considered less feasible given the large number of available diagnostic strategies that can be compared and the consequently required number of patients $[4,10,12-15]$. Moreover, the limited 
time frame of a common RCT does not allow assessment of long-term outcomes or risks related to testing (e.g. radiation risk due to imaging tests) and technological evolution of diagnostics may render the RCT results quickly out-dated. Finally, the overwhelming number of new tests and markers entering the market would require a huge number of diagnostic RCTs for which there may not even be enough patients to recruit. These limitations are also apparent from the low number of such diagnostic (testtreatment) RCTs in current literature [15].

Decision analytic and cost-effectiveness modelling is a valid alternative to diagnostic RCTs to quantify the effects of testing on long terms outcomes and costs. Suitable models can synthesize the evidence from different sources, including pre-clinical studies (e.g. evidence on risks), diagnostic test accuracy studies, and therapeutic intervention studies (e.g. evidence on outcomes) $[4,10,16-18]$. Subsequently, the life course of hypothetical individuals can be simulated while tracking risk factors, complications, quality of life, and costs, to assess the incremental costeffectiveness of a new diagnostic strategy [17,19-21].

In this paper we illustrate decision analytic modelling using an empirical study to assess the long term health effects and cost-effectiveness of using a new diagnostic test, modified transesophageal echocardiography (TEE) as compared to care as usual in patients undergoing cardiac surgery. This test is used to detect aortic atherosclerosis as early as possible in order to prevent embolic stroke caused by emboli merging from the atherosclerotic ascending aorta during surgery. Rather than discussing the potential value of decision analytic modelling in general we show that the cost-effectiveness of modified TEE can be estimated without performing a diagnostic RCT and present the elements and results of our analysis.

\section{Methods}

\section{Description of the example study}

The incidence of ischemic stroke after cardiac surgery is about $3 \%$, accounting for $10-20 \%$ of postoperative deaths [22-25]. As the prevalence of atherosclerosis increases sharply with age from $10 \%$ in patients aged $50-60$ years to at least $35 \%$ in patients older than 75 years, the postcardiac-surgery stroke rate also increases to $7 \%$ in older patients $[26,27]$. Post-operative stroke is often caused by emboli from dislodged atherosclerotic plaques in the ascending aorta, when it is cannulated or clamped $[22,23,28-30]$. Knowing the presence and extent of atherosclerosis prior to sternotomy allows changes in surgical strategy reducing or avoiding manipulation of the ascending aorta, and may therefore reduce the post-operative risk of embolic stroke. Hence, rapid and accurate diagnosis of atherosclerosis in the ascending aorta may result in a decreasing number of ischemic strokes after cardiac surgery caused by emboli.
We compared the modified transesophageal echocardiography (TEE) strategy with the manual palpation strategy. Manual palpation is still the most commonly used method for assessing atherosclerosis in the ascending aorta although it is not very sensitive and may be hazardous, i.e. it may dislodge vulnerable atherosclerotic plaques, which in turn may cause stroke, and it can only be used after sternotomy [31]. The modified TEE method was introduced to enhance conventional TEE by visualizing the distal part of the ascending aorta before incision, using an intra-tracheal balloon-catheter (the A-View catheter, Cordatec Inc. Zoersel, Belgium) to create an ultrasound conducting window $[32,33]$. For both methods epiaortic ultrasound scanning (EU) was used to assess diagnostic accuracy and potential impact on clinical management. Epiaortic ultrasound scanning may be considered the gold standard for detecting ascending aorta atherosclerosis but cannot be applied prior to surgery and is not available in all medical centres $[34,35]$.

\section{Model description}

We used a Markov decision analytic model to assess the differences in long term health benefits and costs of both strategies [19]. In the modified TEE strategy surgery could be adapted due to the presence of atherosclerosis detected pre-sternotomy with modified TEE. In the manual palpation strategy surgery could be adapted due to the presence of atherosclerosis detected with manual palpation after sternotomy.

The decision analytic part of our model (first part) estimated the fraction of cardiac patients that experienced no complications (no stroke), a non-fatal stroke, a fatal stroke, and death due to other causes, separately for each diagnostic strategy (Figure 1A). The outcomes served as input for the Markov model (second part).

Markov models are useful when events can occur at various points in time and with varying probabilities [36]. In a Markov model hypothetical individuals reside in predefined health states and can move from one health state to another in fixed time intervals. We defined the health states 'post-surgery - no complications,' 'post-surgery post stroke', and 'dead', and individuals started in these health states based on the outcome of the decision analytic part of our model (Figure 1B). After a fatal stroke or death due to other causes individuals started, and remained, in the 'dead' state. Individuals in the 'post cardiac surgery no complications' state and the 'post cardiac surgery - post stroke' state could die from causes unrelated to the surgical procedure, and then move to the 'dead' state. Here, the risk of death was based on age and gender specific all-cause Dutch mortality rates (Statistics Netherlands, CBS), apart from the first five years after surgery in which the mortality risk was increased, reflecting the mortality experience of cardiac surgery patients. 


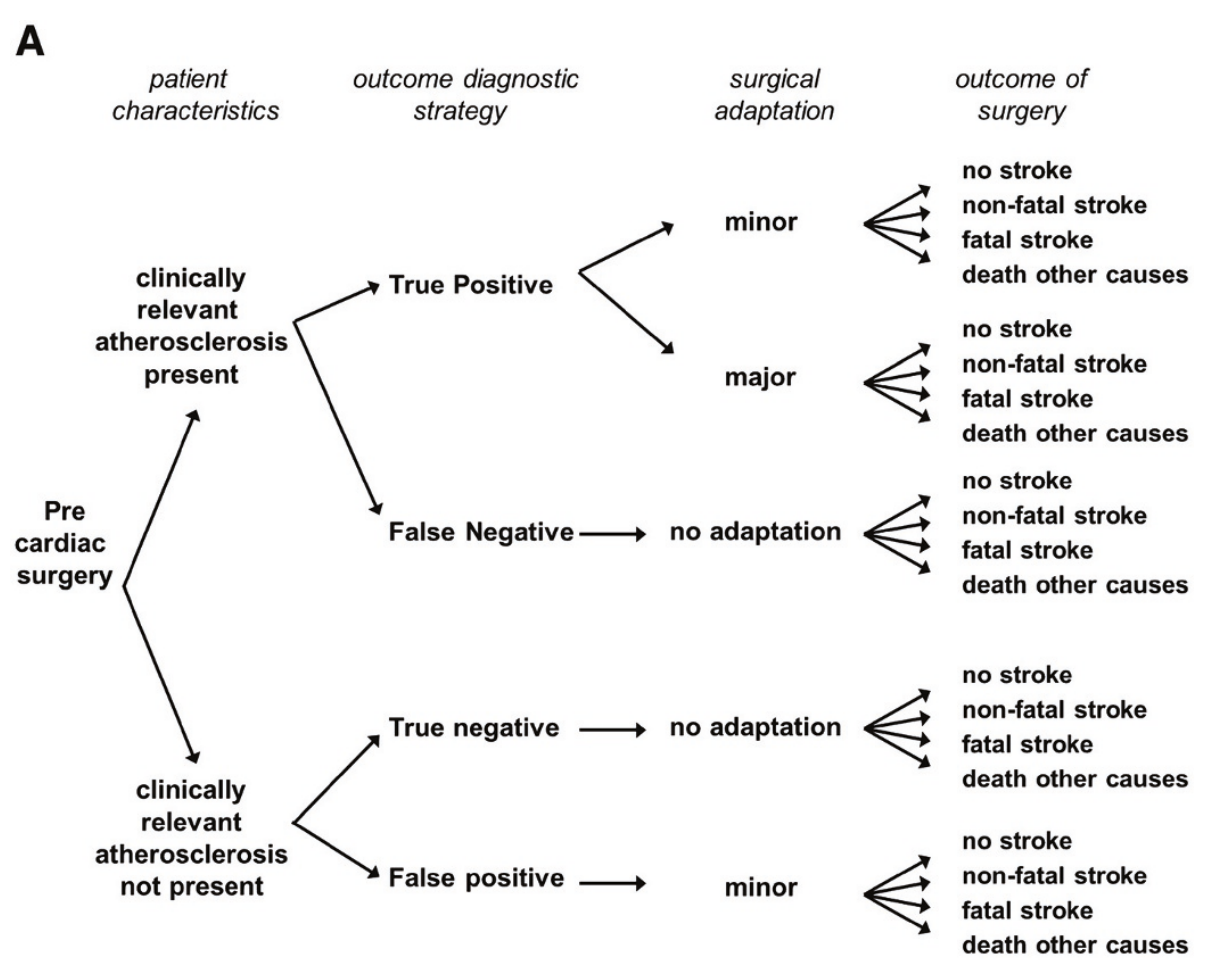

B

surgical outcome health states health state transitions (per year)

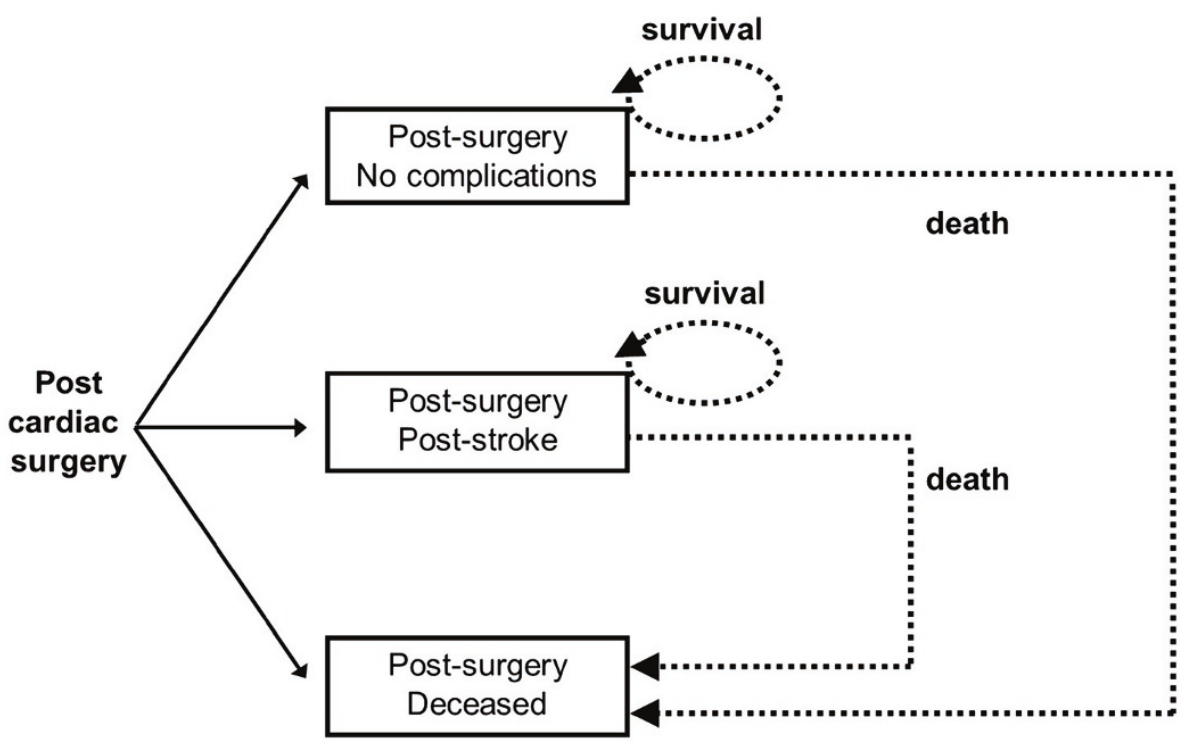

Figure 1 Visualization of the decision analytic part of the model for the manual palpation strategy $[\mathrm{A}]$, and the ensuing Markov part of the model [B]. The structure of the model for the modified TEE strategy is similar.

We assigned an utility, i.e. a quality of life estimate, and costs to each health state in the Markov part of our model, and also accounted for the costs of diagnosis and adaptation in the decision analytic part of our model.
The prevalence of atherosclerosis and the risk of stroke We varied the prevalence of atherosclerosis in our model, allowing it to increase with age, and performed separate analyses for men and women, as accurate data on the age and gender specific prevalence of atherosclerosis is lacking. 
Table 1 The baseline values for model parameters

\begin{tabular}{|c|c|c|c|c|}
\hline Input parameter & Value* & Range\$ & Distribution & Source \\
\hline Probability of early death (within 30 days) & \multicolumn{2}{|c|}{ EuroSCORE risk equation } & & {$[37]$} \\
\hline Probability death is due to fatal stroke event & $13.2 \%$ & $7.5-20.2 \%$ & $\operatorname{Beta}(14,92)$ & [25] \\
\hline Probability that a stroke event is not fatal & $80.8 \%$ & $75.3-85.8 \%$ & $\operatorname{Beta}(173,41)$ & [38] \\
\hline Probability that stroke is caused by emboli & $71.0 \%$ & $63.3-77.8 \%$ & $\operatorname{Beta}(107,44)$ & [38] \\
\hline Manual palpation: sensitivity & $31 \%$ & $22-40 \%$ & $\operatorname{Beta}(33,73)$ & [31] \\
\hline Manual palpation: specificity & $98 \%$ & $96-100 \%$ & $\operatorname{Beta}(179,4)$ & [31] \\
\hline Modified TEE: sensitivity & $97 \%$ & $94-100 \%$ & $\operatorname{Beta}(124,4)$ & [39] \\
\hline Modified TEE: specificity & $80 \%$ & $74-85 \%$ & $\operatorname{Beta}(173,44)$ & [39] \\
\hline $\begin{array}{l}\text { Risk reduction of post-operative stroke due to adaptations } \\
\text { when applying the modified TEE }\end{array}$ & 0.46 & $0.196-0.910$ & $\begin{array}{l}\text { LogNormal }(-0.864 \\
0.392)\end{array}$ & {$[25] \dagger$} \\
\hline $\begin{array}{l}\text { Probability of a major adaptation of surgery given a patient with } \\
\text { atherosclerosis }\end{array}$ & $2.7 \%$ & $2.3-3.1 \%$ & $\operatorname{Beta}(163,5888)$ & [40] \\
\hline Risk of death (year 1-2 post-surgery): age $<61$ years & $1.18 \%$ & $0.82-1.42 \%$ & Uniform & {$[41] \neq$} \\
\hline Risk of death (year 1-5 post-surgery): age $61-70$ years & $2.33 \%$ & $1.95-2.71 \%$ & Uniform & {$[41] \neq$} \\
\hline Risk of death (year 1-5 post-surgery): age $>70$ years & $4.35 \%$ & $3.49-5.24 \%$ & Uniform & {$[41] \neq$} \\
\hline Utility of the 'Post Stroke' health state & 0.439 & $0.186-0.653$ & Triangular & {$[42]^{\wedge}$} \\
\hline Utility of the 'No complications' health state & 1 & - & - & Default \\
\hline Cost of death (Euros) & 2,736 & $1,368-5,471$ & Uniform & $\begin{array}{l}\text { Expert opinion } \\
{[43]}\end{array}$ \\
\hline Diagnostic cost of modified TEE tool (Euros) & 212 & $184-243$ & Gamma & Manufacturer \\
\hline Cost of fatal stroke event (Euros) & 2,736 & $1,368-5,471$ & Uniform & $\#$ \\
\hline Discount rate for costs & $4.0 \%$ & - & - & Dutch guidelines \\
\hline Discount rate for effects & $1.5 \%$ & - & - & Dutch guidelines \\
\hline
\end{tabular}

The baseline values that were used as input parameters for the model, along with their range and distribution (if applicable).

* All costs were recalculated to 2012 euros.

\$ Range concerns the full range for uniform distributions and $95 \%$ confidence intervals for other distribution types.

\# The cost of a fatal stroke was assumed equal to the cost of death, as the costs of additional medical care delivered to stroke patients prior to death is already incorporated in the costs of surgery (Additional file 1).

† This risk reduction was based on the comparison of two groups in the original article: group C (13 strokes in 690 patients) versus group A (12 strokes in 268 patients).

‡ Values were recalculated from the actuarial survival curves by age in the source material and concern annual mortality risks applied in the first five years after cardiac surgery.

$\wedge$ Estimates of the utility of patients after major stroke vary widely therefore a large range was used $(\min =0.11$, max $=0.71$, most likely value $=0.50$, resulting in an expected value of 0.439 ).

In total, we defined 12 subgroups based on gender, age (55, 65, 75 year old patients), and two estimates of the prevalence of distal ascending aorta atherosclerosis across age categories. Low prevalence rates were 10\%, 20\% and $40 \%$ at age 55, 65 and 75 years respectively, and high prevalence rates $15 \%, 30 \%$ and $50 \%$ respectively. As patients can die from a number of complications arising during or after cardiac surgery, we separated fatal stroke events from fatal non-stroke events. Roughly $15 \%$ of all cardiac mortality was attributed to fatal strokes [25]. However, not every stroke needs to be fatal: patients can also experience non-fatal strokes. We included a $38 \%$ probability that a stroke is fatal, giving a $62 \%$ probability that a stroke is non-fatal [25]. Finally, not all strokes are actually caused by emboli merging from the atherosclerotic ascending aorta, some have other causes and cannot, therefore, be prevented by reducing manipulation of the ascending aorta. In our model, $70 \%$ of all strokes were assumed to be embolic and thereby potentially preventable through changes in surgical strategy after detection of atherosclerosis, whereas the remaining 30\% was assumed to have other origins.

\section{Model assumptions}

The following assumptions were required for the costeffectiveness analysis:

1. The beneficial effect from surgical adaptation was similar for minor and for major adaptations (a relative risk of embolic stroke of 0.46 (95\%CI: 0.196- 0.910)). However, major adaptations increased surgical costs, whereas minor adaptations (e.g. relocation of clamps) did not. Also, in patients with a false positive test result only minor adaptations may be performed, as any 
Table 2 Expected probabilities of surgical adaptation and stroke

\begin{tabular}{|c|c|c|c|c|c|c|c|c|c|c|c|c|c|c|}
\hline & \multicolumn{4}{|c|}{ Subgroup } & \multicolumn{5}{|c|}{ Manual palpation strategy } & \multicolumn{5}{|c|}{ Modified TEE strategy } \\
\hline & \multirow[t]{2}{*}{ Gender } & \multirow[t]{2}{*}{ Age } & \multirow[t]{2}{*}{$\%$ atherosclerosis } & \multirow{2}{*}{$\begin{array}{l}\text { EuroSCORE } \\
\text { predicted } \\
\text { mortality risk }\end{array}$} & \multirow{2}{*}{$\begin{array}{c}\text { Chance of } \\
\text { minor adaptation }\end{array}$} & \multirow{2}{*}{$\begin{array}{c}\text { Chance of } \\
\text { major adaptation }\end{array}$} & \multicolumn{2}{|c|}{ Risk of stroke } & \multirow{2}{*}{$\begin{array}{l}\text { Life-years } \\
\text { after surgery }\end{array}$} & \multirow{2}{*}{$\begin{array}{l}\text { Chance } \\
\text { of minor } \\
\text { adaptation }\end{array}$} & \multirow{2}{*}{$\begin{array}{l}\text { Chance } \\
\text { of major } \\
\text { adaptation }\end{array}$} & \multicolumn{2}{|c|}{ Risk of stroke } & \multirow{2}{*}{$\begin{array}{l}\text { Life-years } \\
\text { after } \\
\text { surgery }\end{array}$} \\
\hline & & & & & & & non-fatal & fatal & & & & non-fatal & fatal & \\
\hline 1 & Men & $55 \mathrm{yr}$ & $10 \%$ & $1.04 \%$ & $3.03 \%$ & $0.08 \%$ & $1.01 \%$ & $0.24 \%$ & 23.06 & $9.43 \%$ & $0.26 \%$ & $0.84 \%$ & $0.23 \%$ & 23.10 \\
\hline 2 & Men & $55 \mathrm{yr}$ & $15 \%$ & $1.08 \%$ & $4.54 \%$ & $0.13 \%$ & $1.04 \%$ & $0.24 \%$ & 23.05 & $14.14 \%$ & $0.39 \%$ & $0.86 \%$ & $0.23 \%$ & 23.10 \\
\hline 3 & Women & $55 \mathrm{yr}$ & $10 \%$ & $1.41 \%$ & $3.04 \%$ & $0.08 \%$ & $1.36 \%$ & $0.32 \%$ & 26.09 & $9.43 \%$ & $0.26 \%$ & $1.14 \%$ & $0.31 \%$ & 26.16 \\
\hline 4 & Women & $55 \mathrm{yr}$ & $15 \%$ & $1.46 \%$ & $4.54 \%$ & $0.13 \%$ & $1.40 \%$ & $0.33 \%$ & 26.08 & $14.14 \%$ & $0.39 \%$ & $1.16 \%$ & $0.31 \%$ & 26.15 \\
\hline 5 & Men & $65 \mathrm{yr}$ & $20 \%$ & $1.61 \%$ & $6.07 \%$ & $0.17 \%$ & $1.53 \%$ & $0.36 \%$ & 15.17 & $18.84 \%$ & $0.52 \%$ & $1.25 \%$ & $0.33 \%$ & 15.22 \\
\hline 6 & Men & $65 \mathrm{yr}$ & $30 \%$ & $1.71 \%$ & $9.10 \%$ & $0.25 \%$ & $1.61 \%$ & $0.38 \%$ & 15.15 & $28.29 \%$ & $0.78 \%$ & $1.29 \%$ & $0.33 \%$ & 15.20 \\
\hline 7 & Women & $65 \mathrm{yr}$ & $20 \%$ & $2.14 \%$ & $6.06 \%$ & $0.17 \%$ & $2.05 \%$ & $0.48 \%$ & 17.49 & $18.84 \%$ & $0.52 \%$ & $1.67 \%$ & $0.44 \%$ & 17.56 \\
\hline 8 & Women & $65 \mathrm{yr}$ & $30 \%$ & $2.28 \%$ & $9.10 \%$ & $0.25 \%$ & $2.15 \%$ & $0.50 \%$ & 17.44 & $28.27 \%$ & $0.78 \%$ & $1.71 \%$ & $0.44 \%$ & 17.53 \\
\hline 9 & Men & $75 \mathrm{yr}$ & $40 \%$ & $3.18 \%$ & $12.15 \%$ & $0.34 \%$ & $2.94 \%$ & $0.69 \%$ & 8.73 & $37.72 \%$ & $1.04 \%$ & $2.31 \%$ & $0.59 \%$ & 8.80 \\
\hline 10 & Men & $75 \mathrm{yr}$ & $50 \%$ & $3.36 \%$ & $15.13 \%$ & $0.42 \%$ & $3.10 \%$ & $0.72 \%$ & 8.70 & $47.13 \%$ & $1.31 \%$ & $2.39 \%$ & $0.60 \%$ & 8.77 \\
\hline 11 & Women & $75 \mathrm{yr}$ & $40 \%$ & $4.13 \%$ & $12.13 \%$ & $0.34 \%$ & $3.83 \%$ & $0.90 \%$ & 10.44 & $37.70 \%$ & $1.04 \%$ & $3.02 \%$ & $0.77 \%$ & 10.55 \\
\hline 12 & Women & $75 \mathrm{yr}$ & $50 \%$ & $4.34 \%$ & $15.21 \%$ & $0.42 \%$ & $4.02 \%$ & $0.94 \%$ & 10.40 & $47.11 \%$ & $1.31 \%$ & $3.09 \%$ & $0.78 \%$ & 10.53 \\
\hline
\end{tabular}

The probabilities and life-years observed from the model. For both strategies the observed chance of adaptation of the surgical procedure is shown, the observed risk of stroke and the expected number of life-years following surgery. In addition, the EuroSCORE predicted mortality risk is given for each subgroup. 
major adaptation is assumed to immediately reveal the incorrect test outcome, and to be aborted as a result.

2. To quantify the expected peri-operative mortality of patients in our model correctly for both strategies, all patients with atherosclerosis in the ascending aorta had the risk factor extra-cardiac arteriopathy as defined in the EuroSCORE risk equation. Consequently, patients with atherosclerosis in the ascending aorta had a higher risk of early mortality than patients without atherosclerosis.

3. The impact of increasing age on quality of life of individuals was assumed to similar for healthy individuals and individuals surviving a stroke. The utility of healthy individuals was therefore set to 1 and the impact of stroke was defined as a reduction in utility from 1 to 0.439 , on average.

\section{Cost-effectiveness analysis}

We defined two baseline groups: 65-year old men and 65 -year old women, both with a prevalence of $20 \%$ atherosclerosis, because these groups contain the largest number of patients seen in clinical practice. For each of the 12 subgroups defined, a hypothetical cohort of 10,000 patients was simulated and the individual pathways of the patients were determined, tracking events, costs, and quality of life, for both diagnostic strategies. Average results were then calculated for each hypothetical cohort. A life time horizon was used, that is, simulation stopped when all patients had moved to the 'dead' state, with time intervals (cycles) of one year. We applied a health care perspective. Costs were estimated in euros $(1$ euro $=1.28$ US\$, September 10 2012). Costs were discounted with $4.0 \%$ and effects with
$1.5 \%$ according to Dutch guidelines. Based on the difference in health benefits and costs we calculated the incremental cost-effectiveness ratio (ICER). Probabilistic sensitivity analysis was performed by Monte Carlo simulation, and 5,000 simulations were performed to account for parameter uncertainty based on the distributions defined in Table 1. All simulations were performed with TreeAge Pro 2011 software (Williamstown, MA, USA).

\section{Results}

Pre-existing evidence on the accuracy of the two

\section{diagnostic strategies}

For manual palpation we found a sensitivity of 31\% (95\% CI: $22-40 \%)$ and a specificity of $98 \%$ (95\%CI: $96-100 \%)$ when compared with EU [31]. For modified TEE a crude sensitivity of $97 \%$ (95\%CI: 94-100\%) and specificity of $80 \%$ (95\%CI: 74-85\%) has been reported [39]. These estimates were used in the model and relate to severe atheroma which, when observed, would require adaptation of the surgical procedure (Table 1). For both diagnostic strategies false positive results could result in minor adaptations, and false negative results caused a lack of adaptations resulting in increased risk of embolic stroke.

\section{Expected early mortality in cardiac surgical patients}

We used the logistic version of the validated EuroSCORE risk equation (comparable with the STS database) to predict early (within 30 days) mortality of the patients in our model $[37,44,45]$. The prevalence of the risk factors included in the EuroSCORE was derived from the literature [45]. The risks predicted by the EuroSCORE equation are substantially higher than currently observed

Table 3 Expected costs and effects for the predefined patient subgroups

\begin{tabular}{|c|c|c|c|c|c|c|c|c|c|c|}
\hline & & Subg & roup & Manual pa & on strategy & Modified & strategy & Modified & TEE vs Manual & alpation \\
\hline & Gender & Age & $\%$ atherosclerosis & $\begin{array}{l}\text { Expected } \\
\text { costs } \\
(€)\end{array}$ & $\begin{array}{l}\text { Expected } \\
\text { effects } \\
\text { (QALY) }\end{array}$ & $\begin{array}{l}\text { Expected } \\
\text { costs } \\
(€)\end{array}$ & $\begin{array}{l}\text { Expected } \\
\text { effects } \\
(\text { QALY) }\end{array}$ & $\begin{array}{c}\text { Expected } \\
\text { incremental } \\
\text { costs }(€)\end{array}$ & $\begin{array}{c}\text { Expected } \\
\text { incremental } \\
\text { effects (QALY) }\end{array}$ & $\begin{array}{c}\text { Expected } \\
\text { ICER } \\
(€ / \text { QALY) }\end{array}$ \\
\hline 1 & Men & $55 \mathrm{yr}$ & $10 \%$ & 25,896 & 14.31 & 25,943 & 14.32 & 47 & 0.01 & 4,651 \\
\hline 2 & Men & $55 \mathrm{yr}$ & $15 \%$ & 25,936 & 14.31 & 25,970 & 14.32 & 34 & 0.01 & 3,376 \\
\hline 3 & Women & $55 \mathrm{yr}$ & $10 \%$ & 25,984 & 15.34 & 25,993 & 15.36 & 10 & 0.02 & 481 \\
\hline 4 & Women & $55 \mathrm{yr}$ & $15 \%$ & 26,012 & 15.33 & 26,009 & 15.36 & -3 & 0.03 & $-103^{*}$ \\
\hline 5 & Men & $65 \mathrm{yr}$ & $20 \%$ & 26,589 & 10.75 & 26,581 & 10.77 & -8 & 0.02 & $-420^{*}$ \\
\hline 6 & Men & $65 \mathrm{yr}$ & $30 \%$ & 26,671 & 10.74 & 26,639 & 10.76 & -32 & 0.02 & $-1,603^{*}$ \\
\hline 7 & Women & $65 \mathrm{yr}$ & $20 \%$ & 26,720 & 11.83 & 26,662 & 11.86 & -58 & 0.03 & $-1,946^{*}$ \\
\hline 8 & Women & $65 \mathrm{yr}$ & $30 \%$ & 26,815 & 11.80 & 26,722 & 11.84 & -93 & 0.04 & $-2,318^{*}$ \\
\hline 9 & Men & $75 \mathrm{yr}$ & $40 \%$ & 27,629 & 7.01 & 27,479 & 7.04 & -149 & 0.03 & $-4,973^{*}$ \\
\hline 10 & Men & $75 \mathrm{yr}$ & $50 \%$ & 27,733 & 6.99 & 27,547 & 7.03 & -186 & 0.04 & $-4,648^{*}$ \\
\hline 11 & Women & $75 \mathrm{yr}$ & $40 \%$ & 28,563 & 8.10 & 28,182 & 8.15 & -380 & 0.05 & $-7,608^{*}$ \\
\hline 12 & Women & $75 \mathrm{yr}$ & $50 \%$ & 28,719 & 8.08 & 28,264 & 8.14 & -455 & 0.06 & $-7,579^{*}$ \\
\hline
\end{tabular}

Cost and effect outcomes for each of the 12 predefined patient subgroups (see text). For both strategies the costs and effects are given, as well as the incremental costs and effects and the incremental cost-effectiveness ratio (ICER).

* In this scenario the modified TEE strategy dominated the manual palpation strategy. 


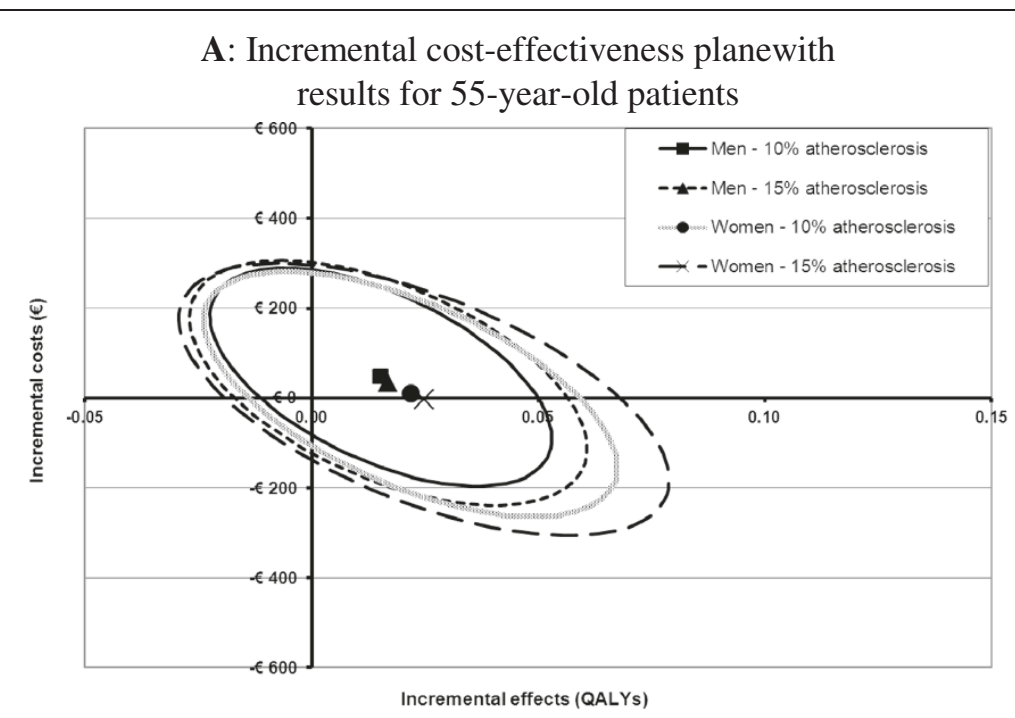

B: Incremental cost-effectiveness plane with

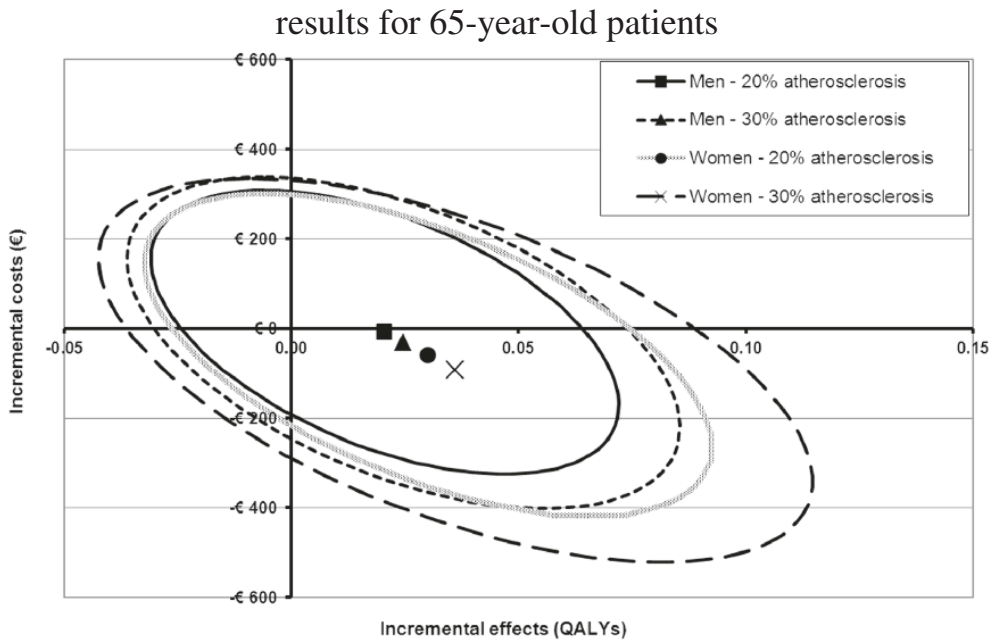

C: Incremental cost-effectiveness plane with results for 75-year-old patients

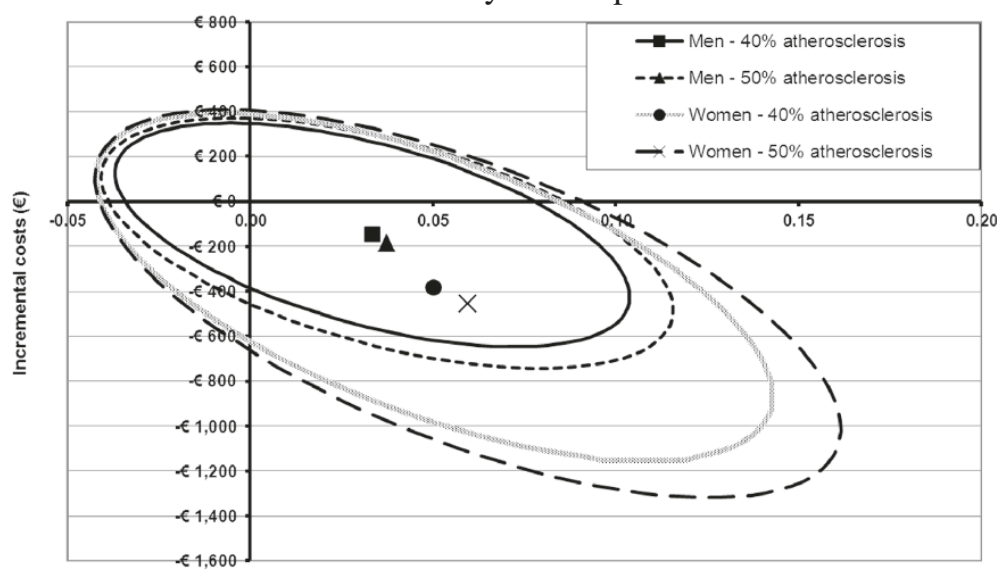

Incremental effects (QALYs)

Figure 2 (See legend on next page.) 
(See figure on previous page.)

Figure 2 The cost-effectiveness plane with incremental costs and effects for 55-year old patients [A], 65-year old patients [B], and 75-year old patients [C]. These figures show the incremental effects (x-axis) and incremental costs (y-axis) of the modified TEE strategy. Each of the 12 subgroups is visualized by an ellipsoid that represents the combined bivariate $95 \%$ confidence interval (Cl) for incremental costs and effects, and a symbol denoting the mean incremental costs and effects. The scales of the axes in Figures $2 \mathrm{~A}-\mathrm{C}$ are not similar, as the range of incremental costs and effects increases with patient age.

in the Netherlands, therefore, we reduced the predicted risks for our cohort of patients by $71 \%$, the reduction found in a large study on fast-track anaesthesia in cardiac surgery $[41,46]$.

\section{Impact of diagnostic tests on surgical management, costs, and the risk of embolic stroke}

In the model, application of the modified TEE method was expected to result in major adaptations in $2.7 \%$ (95\%CI: $2.3-3.1 \%)$ of all patients with detected atherosclerosis, similar to the influence of EU on intraoperative surgical management [40]. Half of these adaptations were in patients undergoing coronary artery bypass grafting $(\mathrm{CABG})$ or single valve surgery procedure, and half in complex CABG (> 2 arterial grafts), CABG + single valve or double valve procedure. The adaptations all consisted of ascending aorta replacement with CABG. On patient level, the mean cost of surgery without adaptation equals $€ 15,628$, and of surgery with major adaptation $€ 23,886$. However, major adaptations occur only in $2.7 \%$ of all patients with atherosclerosis, rendering the overall 'weighted' mean costs rather similar, i.e. $€ 15,628$ without adaptation and $€ 15,842$ with the occasional major adaptation (see Additional file 1). In both strategies the detection of atherosclerosis in the remaining $100-2.7 \%=97.3 \%$ of patients with atherosclerosis resulted in minor surgical adaptations, without cost consequences, such as changing the cannulation site and changing the aortic clamping site. The cost of the modified TEE intervention itself was relatively small $(€ 212,-)$, as the balloon-catheter is made from inexpensive materials, and the modified TEE imaging procedure takes, on average, only 4.5 minutes to perform [33]. Finally, surgical adaptation was estimated to incur a relative risk of post-operative embolic stroke of 0.46 (95\%CI: 0.196-0.910) [25]. Details on costs of cardiac procedures, non-fatal strokes, and potential major changes in surgical procedures are provided in the Additional file 1.

\section{Cost-effectiveness outcomes}

Table 2 presents the intermediate outcomes of the analysis, the predicted mortality risk, the risk of stroke, the probability of adaptation, and the expected number of life years after surgery. As expected, for both the manual palpation strategy and the modified TEE strategy more adaptation occurred with increasing prevalence of atherosclerosis (Table 2). The risk of fatal and non-fatal stroke events also increased with this prevalence and with age, for both strategies. The number of life-years after cardiac surgery decreased rapidly with patient age, but only slightly with increasing prevalence of atherosclerosis, for both strategies. The risk of stroke was higher in women than in men, as female sex is a risk factor in the EuroSCORE risk equation. However, the life-expectancy after surgery was still higher among women. For all patient subgroups, the modified TEE strategy consistently resulted in a larger number of adapted procedures and, consequently, in a lower risk of stroke and a slightly higher number of life-years.

For both strategies costs increased and health effects decreased with increasing patient age, whereas increasing prevalence of atherosclerosis had very limited influence (Table 3). In our main scenario concerning 65 year old men with $20 \%$ atherosclerosis manual palpation resulted in costs of $€ 26,589$ to gain 10.75 Quality-adjusted lifeyears (QALYs), and modified TEE resulted in costs of $€$ 26,581 to gain 10.77 QALYs. In the corresponding scenario for women, costs and effects were $€ 26,720$ and 11.83 QALYs for manual palpation and $€ 26,662$ and 11.86 QALYs for modified TEE, respectively. The modified TEE strategy was slightly more expensive in 55-year-old patients, i.e. subgroups 1-3, and just cost-saving in 65-year-old patients (Table 3). In 75-year-old patients modified TEE offered substantial cost-savings. Cost-savings were higher in women than in men. Furthermore, the modified TEE strategy resulted in small health gains, increasing with age, in all subgroups. Accordingly, the incremental costeffectiveness ratio (ICER) was positive in subgroup 1-3, indicating additional health at additional cost, with a maximum ICER of $€ 4,651$ per QALY. In all other subgroups the ICER was negative indicating additional health at reduced cost. Here the modified TEE strategy dominated the manual palpation strategy.

Figures $2 \mathrm{~A}-\mathrm{C}$ depict the uncertainty surrounding the cost-effectiveness results shown in Table 3 . In these figures the ellipsoids indicate the $95 \%$ confidence regions for incremental cost and effects, for different subgroups of patients, based on the results from the probabilistic sensitivity analysis. In all figures the largest proportion of the ellipsoids is located either the north-eastern or southeastern quadrants of the plane, indicating that the modified TEE is expected to result in health gain. To some extent the ellipsoids also cover the north-western 


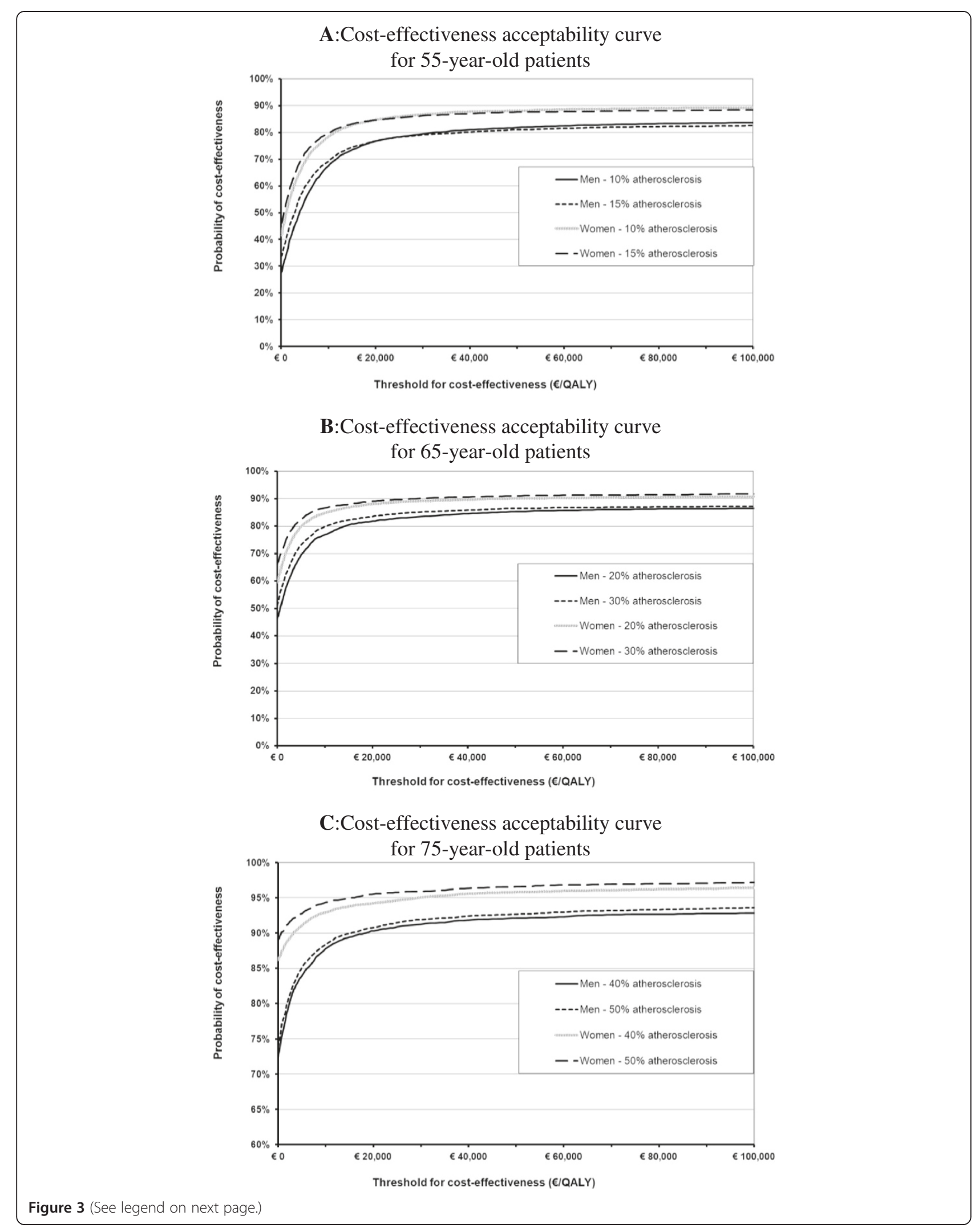


(See figure on previous page.)

Figure 3 Cost-effectiveness acceptability curves indicating the probability that the modified TEE strategy is cost-effective for 55-year old patients $[A], 65$-year old patients $[B]$, and 75-year old patients $[C]$, as function of a range of cost-effectiveness threshold values. The intersections of the curves with the vertical axis indicate the probability that the modified TEE strategy is cost-saving and results in health gain, i.e. the probability that the cost-effectiveness is still acceptable even if a decision-maker is unwilling to pay anything for additional health gain. The $y$-axis of Figure $3 C$ was adjusted for visual clarity.

quadrant, indicating increased costs and worse health outcomes for the modified TEE strategy. Comparing men and women in Figures $2 \mathrm{~A}-\mathrm{C}$ it appeared that the uncertainty was consistently larger for women than for men, and increased with the prevalence of atherosclerosis and age. In addition, larger proportions of the ellipsoids were located in the south-eastern quadrant. Thus, the probability of the modified TEE strategy resulting in cost saving and health gain increased although the exact cost-saving and health gain became more uncertain.

Figures $3 \mathrm{~A}-\mathrm{C}$ shows cost-effectiveness acceptability curves indicating the probability that the cost-effectiveness of the modified TEE strategy would be acceptable for various costeffectiveness threshold (CET) values [47]. In Figures 3A-C the intersections of the curves with the vertical axis indicate the probability that the modified TEE strategy is costsaving and results in health gain, i.e. the probability that the cost-effectiveness is still acceptable even if a decisionmaker is unwilling to pay anything for additional health gain. Figure 3A shows that for 55-year-old patients this probability ranged from $27 \%$ for men (prevalence atherosclerosis $10 \%$ ) to $46 \%$ for women (prevalence atherosclerosis $15 \%)$. Figure 3B shows that for 65 -year-old patients this ranged from $46 \%$ for men (prevalence atherosclerosis $20 \%$ ) to $66 \%$ for women (prevalence atherosclerosis $30 \%$ ), and for 75-year-old patients this probability ranged from $72 \%$ for men (prevalence atherosclerosis $40 \%$ ) to $89 \%$ for women (prevalence atherosclerosis 50\%) (Figure 3C). Considering a cost-effectiveness threshold of $€ 20,000 /$ QALY as applied in The Netherlands, the probability that modified TEE has acceptable cost-effectiveness is at least $77 \%$ for 55 -year-old patients, at least $82 \%$ for 65 -year-old patients, and at least $90 \%$ for 75 -year-old patients.

\section{Discussion}

In this paper we demonstrated the value of a comprehensive decision analytic approach in a specific case study on the prevention of post-operative embolic stroke in cardiac surgery patients using different diagnostic test strategies. With respect to our case study it has been shown previously that the modified TEE strategy allows imaging of the atherosclerosis of the distal part of the ascending aorta without severe and unexpected adverse effects [33]. Here we find that the cost-effectiveness of the modified TEE strategy compared with the manual palpation strategy varies with patient age and gender, and with the prevalence of atherosclerosis of the ascending aorta. Nevertheless, our results indicate that, in comparison with manual palpation, the modified TEE strategy is expected to be costsaving and beneficial in all patients undergoing cardiac surgery from the age of 65 years, also for low prevalence rates of atherosclerosis. In patients 55 to 65 year old, however, the modified TEE strategy is expected to result in small health benefits at very low costs, with a probability of acceptable cost-effectiveness of $>77 \%$ given the Dutch threshold of $€ 20,000 / \mathrm{QALY}$.

\section{Limitations of the case study analysis}

Our model has certain limitations. First, to obtain an estimate of the risk of death in patients with atherosclerosis in the ascending aorta after cardiac surgery we used the increased risk of patients with arteriopathy as based on the EuroSCORE. This assumption was necessary because accurate evidence on the true excess risk of death due to atherosclerosis in the ascending aorta when undergoing cardiac surgery is lacking. Second, there are no clear estimates of the prevalence of atherosclerosis in the ascending aorta in patients undergoing cardiac surgery, certainly not as a function of patient age. We resolved this issue by defining 12 different patient subgroups with two prevalence rates per age category. We found that the cost-effectiveness results were rather similar for both low and high prevalence rates of atherosclerosis per age category. Finally, the incidence of embolic stroke increases with the complexity of the surgical technique (maximum for combined cardiac surgery and carotid endarterectomy procedures, followed by surgery of the thoracic aorta and combined valve and CABG surgery). However, evidence on the risk of embolic stroke per surgical technique is lacking and could therefore not be included in the analysis.

In the past two decades, diagnostic research methodology has progressed rapidly and in many directions, but important challenges remain [48]. As diagnostic RCTs to assess the long term effects of a new diagnostic test, marker or strategy are often inefficient, infeasible or too time consuming [4,10,12-15], decision analytic and cost-effectiveness modelling can be a valuable alternative. Such approach may synthesize all available evidence to provide insight into the effects of diagnostic strategies, through downstream clinical management, on patient outcomes and costs-effectiveness, both short and long term. Examples of decision analytic models used in cost-effectiveness analysis of diagnostic tests 
can be found in the literature, but are often limited in their approach $[49,50]$. For example, they do not include and synthesize relevant evidence on all possible diagnostic pathways, or focus only on short term consequences, or perform only limited sensitivity analysis.

Cost-effectiveness models for evaluating diagnostic tests will, in general, be more complex and require more evidence, than cost-effectiveness models for evaluating therapeutic interventions. However, we showed that cost-effectiveness modelling of diagnostics tests is feasible and can rapidly, at relatively low costs, provide insights into the value of the use or introduction of a new test or marker in terms of improved patient outcomes. Moreover, models can be readily updated when new evidence - e.g. on new treatments or new tests becomes available. Furthermore, model-based methods can be used to determine whether a diagnostic RCT may still be worthwhile to conduct and in which specific patient groups, to optimize RCT design [19,51].

\section{Conclusion}

Our analysis demonstrates how to use a decision analytic and cost-effectiveness modelling approach to assess the long term cost-effectiveness of a new diagnostic test, marker or strategy - as compared to existing tests or strategies - without doing a formal RCT. The approach combines evidence on the costs and direct risks of the test from early clinical studies, on the performance of the test as compared to the existing reference standard from test accuracy studies, and evidence on the effects of subsequent treatments as obtained from treatment follow-up studies. Our case study suggests that modified transesophageal echocardiography may reduce the risk of embolic stroke in cardiac surgery patients older than 55 years at acceptable cost-effectiveness levels.

\section{Additional file}

\section{Additional file 1: Definition of the surgical procedures and cost of} stroke.

\section{Abbreviations \\ CABG: Coronary artery bypass grafting; CET: Cost-effectiveness threshold; Cl: Confidence interval; EU: Epiaortic ultrasound scanning; ICER: Incremental cost-effectiveness ratio; Modified TEE: Modified transesophageal echocardiography; QALY: Quality-adjusted life-year; RCT: Randomized clinical trial. \\ Competing interests \\ The authors declare that they have no competing interests.}

\section{Authors' contributions}

HK developed the decision analytic model, analysed the results and drafted the manuscript. BZ acquired the input data for the model, critically assessed and interpreted the results, and contributed to drafting the manuscript. KGMM conceived the study, participated in interpretation of the results and contributed to drafting the manuscript. All authors have given final approval of the version to be published.

\section{Acknowledgements}

B. van Zaane and K.G.M. Moons have received a grant of ZonMw, The Netherlands Organization for Health Research and Development (\# 945.27.009) for studying the diagnostic accuracy of the modified TEE method. H. Koffijberg has received a grant from NWO, The Netherlands Organisation for Scientific Research (\# 916.11.126), for studying methods enhancing the economic evaluation of diagnostic tests. The funding bodies had no role in the design, collection, analysis, and interpretation of data, or in the writing of the manuscript; and in the decision to submit the manuscript for publication.

\section{Author details}

${ }^{1}$ Julius Centre for Health Sciences and Primary Care, University Medical Centre Utrecht, Mailstop STR 6.131, P.O. Box 85500, Utrecht, GA 3508, The Netherlands. ${ }^{2}$ Division of Perioperative Care and Emergency Medicine, University Medical Centre Utrecht, Utrecht, The Netherlands.

Received: 30 October 2012 Accepted: 24 January 2013

Published: 31 January 2013

\section{References}

1. Welch HG, Black WC: Overdiagnosis in cancer. J Natl Cancer Inst 2010, 102:605-613.

2. Welch HG: Overdiagnosis and mammography screening. BMJ 2009, 339:b1425.

3. Price $\mathrm{CP}$, Christenson $\mathrm{RH}$ : Evaluating new diagnostic technologies: perspectives in the UK and US. Clin Chem 2008, 54:1421-1423.

4. Moons KG: Criteria for scientific evaluation of novel markers: a perspective. Clin Chem 2010, 56:537-541.

5. Bossuyt PM, Reitsma JB, Linnet K, Moons KG: Beyond diagnostic accuracy: the clinical utility of diagnostic tests. Clin Chem 2012, 58(12):1636-1643.

6. Ferrante Di Ruffano L, Hyde CJ, McCaffery KJ, Bossuyt PM, Deeks JJ: Assessing the value of diagnostic tests: a framework for designing and evaluating trials. BMJ 2012, 344:e686.

7. Bossuyt PM, Irwig L, Craig J, Glasziou P: Comparative accuracy: assessing new tests against existing diagnostic pathways. BMJ 2006, 332:1089-1092.

8. Lijmer JG, Leeflang M, Bossuyt PM: Proposals for a phased evaluation of medical tests. Med Decis Making 2009, 29:E13-E21.

9. Gluud C, Gluud LL: Evidence based diagnostics. BMJ 2005, 330:724-726.

10. Biesheuvel CJ, Grobbee DE, Moons KG: Distraction from randomization in diagnostic research. Ann Epidemiol 2006, 16:540-544.

11. Van den Bruel A, Cleemput I, Aertgeerts B, Ramaekers D, Buntinx F: The evaluation of diagnostic tests: evidence on technical and diagnostic accuracy, impact on patient outcome and cost-effectiveness is needed. J Clin Epidemiol 2007, 60:1116-1122.

12. Hlatky MA, Greenland P, Arnett DK, Ballantyne CM, Criqui MH, Elkind MS, Go AS, Harrell FE Jr, Hong Y, Howard BV, et al: Criteria for evaluation of novel markers of cardiovascular risk: a scientific statement from the American Heart Association. Circulation 2009, 119:2408-2416.

13. Bossuyt PM, Lijmer JG, Mol BW: Randomised comparisons of medical tests: sometimes invalid, not always efficient. Lancet 2000, 356:1844-1847.

14. Lord SJ, Irwig L, Simes RJ: When is measuring sensitivity and specificity sufficient to evaluate a diagnostic test, and when do we need randomized trials? Ann Intern Med 2006, 144:850-855.

15. Ferrante Di Ruffano L, Davenport C, Eisinga A, Hyde C, Deeks JJ: A capturerecapture analysis demonstrated that randomized controlled trials evaluating the impact of diagnostic tests on patient outcomes are rare. J Clin Epidemiol 2012, 65:282-287.

16. Schaafsma JD, Van Der Graaf Y, Rinkel GJ, Buskens E: Decision analysis to complete diagnostic research by closing the gap between test characteristics and cost-effectiveness. J Clin Epidemio/ 2009, 62:1248-1252.

17. Hunink MGM, Glasziou PP, Siegel JE, Weeks JC, Pliskin JS, Elstein AS, Weinstein MC: Decision Making in Health and Medicine: Integrating Evidence and Values. Cambridge, UK: Cambridge University Press; 2001.

18. Bossuyt PM, McCaffery K: Additional patient outcomes and pathways in evaluations of testing. Med Decis Making 2009, 29:E30-E38.

19. Briggs $\mathrm{AH}$, Sculpher $\mathrm{M}$, Claxton K: Decision Modelling for Health Economic Evaluation. Oxford: Oxford University Press; 2006. 
20. Hunink MG, Gazelle GS: CT screening: a trade-off of risks, benefits, and costs. J Clin Invest 2003, 111:1612-1619.

21. Henriksson M, Palmer S, Chen R, Damant J, Fitzpatrick NK, Abrams K, Hingorani AD, Stenestrand U, Janzon M, Feder G, et al: Assessing the cost effectiveness of using prognostic biomarkers with decision models: case study in prioritising patients waiting for coronary artery surgery. BMJ 2010, 340:b5606.

22. Almassi GH, Sommers T, Moritz TE, Shroyer AL, London MJ, Henderson WG Sethi GK, Grover FL, Hammermeister KE: Stroke in cardiac surgical patients: determinants and outcome. Ann Thorac Surg 1999, 68:391-397.

23. Llinas R, Barbut D, Caplan LR: Neurologic complications of cardiac surgery. Prog Cardiovasc Dis 2000, 43:101-112.

24. Roach GW, Kanchuger M, Mangano CM, Newman M, Nussmeier N, Wolman R, Aggarwal A, Marschall K, Graham SH, Ley C: Adverse cerebral outcomes after coronary bypass surgery. Multicenter study of perioperative ischemia research group and the ischemia research and education foundation investigators. N Engl J Med 1996, 335:1857-1863.

25. Zingone B, Rauber E, Gatti G, Pappalardo A, Benussi B, Dreas L, Lattuada L: The impact of epiaortic ultrasonographic scanning on the risk of perioperative stroke. Eur J Cardiothorac Surg 2006, 29:720-728.

26. Dávila-Román VG, Barzilai B, Wareing TH, Murphy SF, Schechtman KB, Kouchoukos NT: Atherosclerosis of the ascending aorta. Prevalence and role as an independent predictor of cerebrovascular events in cardiac patients. Stroke 1994, 25:2010-2016.

27. Blauth $\mathrm{Cl}$, Cosgrove DM, Webb BW, Ratliff NB, Boylan M, Piedmonte MR, Lytle BW, Loop FD: Atheroembolism from the ascending aorta. An emerging problem in cardiac surgery. J Thorac Cardiovasc Surg 1992, 103:1104-1111.

28. Amarenco P, Cohen A, Tzourio C, Bertrand B, Hommel M, Besson G, Chauvel C, Touboul PJ, Bousser MG: Atherosclerotic disease of the aortic arch and the risk of ischemic stroke. N Engl J Med 1994, 331:1474-1479.

29. Hartman GS, Yao FS, Bruefach M III, Barbut D, Peterson JC, Purcell MH, Charlson ME, Gold JP, Thomas SJ, Szatrowski TP: Severity of aortic atheromatous disease diagnosed by transesophageal echocardiography predicts stroke and other outcomes associated with coronary artery surgery: a prospective study. Anesth Analg 1996, 83:701-708.

30. Mohan R, Amsel BJ, Walter PJ: Coronary artery bypass grafting in the elderly-a review of studies on patients older than 64,69 or 74 years. Cardiology 1992, 80:215-225.

31. Royse C, Royse A, Blake D, Grigg L: Screening the thoracic aorta for atheroma: a comparison of manual palpation, transesophageal and epiaortic ultrasonography. Ann Thorac Cardiovasc Surg 1998, 4:347-350.

32. Nierich AP, van Zaane B, Buhre WF, Coddens J, Spanjersberg AJ, Moons KG: Visualization of the distal ascending aorta with A-Mode transesophageal echocardiography. J Cardiothorac Vasc Anesth 2008, 22:766-773.

33. Van Zaane B, Nierich AP, Buhre WF, Brandon Bravo Bruinsma GJ, Moons KG: Resolving the blind spot of transoesophageal echocardiography: a new diagnostic device for visualizing the ascending aorta in cardiac surgery. Br J Anaesth 2007, 98:434-441.

34. Konstadt SN, Reich DL, Kahn R, Viggiani RF: Transesophageal echocardiography can be used to screen for ascending aortic atherosclerosis. Anesth Analg 1995, 81:225-228.

35. Ostrowski JW, Kanchuger MS: Con: epiaortic scanning is not routinely necessary for cardiac surgery. J Cardiothorac Vasc Anesth 2000, 14:91-94.

36. Sonnenberg FA, Beck JR: Markov models in medical decision making: a practical guide. Med Decis Making 1993, 13:322-338.

37. Roques F, Michel P, Goldstone AR, Nashef SA: The logistic EuroSCORE. Eur Heart J 2003, 24:881-882.

38. Salazar JD, Wityk RJ, Grega MA, Borowicz LM, Doty JR, Petrofski JA Baumgartner WA: Stroke after cardiac surgery: short- and long-term outcomes. Ann Thorac Surg 2001, 72:1195-1201.

39. Van Zaane B, Nierich AP, Brandon Bravo Bruinsma GJ, Rosseel PM, Ramjankhan FZ, de Waal EE, Buhre WF, Moons KG: Diagnostic accuracy of modified transoesophageal echocardiography for pre-incision assessment of aortic atherosclerosis in cardiac surgery patients. Br J Anaesth 2010, 105:131-138.

40. Rosenberger P, Shernan SK, Loffler M, Shekar PS, Fox JA, Tuli JK, Nowak M, Eltzschig HK: The influence of epiaortic ultrasonography on intraoperative surgical management in 6051 cardiac surgical patients. Ann Thorac Surg 2008, 85:548-553.
41. Keogh BE, Kinsman R: The Society of Cardiothoracic Surgeons of Great Britain and Ireland: Fifth National Adult Cardiac Surgical Database Report 2003. 59A Bell Street, Henley-on-Thames, Oxfordshire RG9 2BA, United Kingdom: Dendrite Clinical Systems Ltd; 2004.

42. Post PN, Stiggelbout AM, Wakker PP: The utility of health states after stroke: a systematic review of the literature. Stroke 2001, 32:1425-1429.

43. Buskens E, Nederkoorn PJ, Buijs-Van Der Woude T, Mali WP, Kappelle L, Eikelboom BC, Van Der Graaf Y, Hunink MG: Imaging of carotid arteries in symptomatic patients: cost-effectiveness of diagnostic strategies. Radiology 2004, 233:101-112.

44. Nashef SA, Roques F, Hammill BG, Peterson ED, Michel P, Grover FL, Wyse RK, Ferguson TB: Validation of European System for Cardiac Operative Risk Evaluation (EuroSCORE) in North American cardiac surgery. Eur J Cardiothorac Surg 2002, 22:101-105.

45. Roques F, Nashef SA, Michel P, Gauducheau E, de Vincentiis C, Baudet E, Cortina J, David M, Faichney A, Gabrielle F, et al: Risk factors and outcome in European cardiac surgery: analysis of the EuroSCORE multinational database of 19030 patients. Eur J Cardiothorac Surg 1999, 15:816-822.

46. Svircevic V, Nierich AP, Moons KG, Brandon Bravo Bruinsma GJ, Kalkman CJ, Van Dijk D: Fast-track anesthesia and cardiac surgery: a retrospective cohort study of 7989 patients. Anesth Analg 2009, 108:727-733.

47. van Hout BA, Al MJ, Gordon GS, Rutten FF: Costs, effects and C/E-ratios alongside a clinical trial. Health Econ 1994, 3:309-319.

48. Buntinx F, Knottnerus JA: Are we at the start of a new era in diagnostic research? J Clin Epidemiol 2006, 59:325-326.

49. Priest VL, Scuffham PA, Hachamovitch R, Marwick TH: Cost-effectiveness of coronary computed tomography and cardiac stress imaging in the emergency department: a decision analytic model comparing diagnostic strategies for chest pain in patients at low risk of acute coronary syndromes. JACC Cardiovasc Imaging 2011, 4:549-556.

50. Wan MJ, Krahn M, Ungar WJ, Caku E, Sung L, Medina LS, Doria AS: Acute appendicitis in young children: cost-effectiveness of US versus CT in diagnosis-a Markov decision analytic model. Radiology 2009, 250:378-386.

51. Willan AR, Goeree R, Boutis K: Value of information methods for planning and analyzing clinical studies optimize decision making and research planning. J Clin Epidemiol 2012, 65:870-876.

doi:10.1186/1471-2288-13-12

Cite this article as: Koffijberg et al.: From accuracy to patient outcome and cost-effectiveness evaluations of diagnostic tests and biomarkers: an exemplary modelling study. BMC Medical Research Methodology 2013 13:12.

\section{Submit your next manuscript to BioMed Central and take full advantage of:}

- Convenient online submission

- Thorough peer review

- No space constraints or color figure charges

- Immediate publication on acceptance

- Inclusion in PubMed, CAS, Scopus and Google Scholar

- Research which is freely available for redistribution 